\title{
POROKERATOSIS OF MIBELLI WITH ORAL LESIONS
}

Selva Prabu S. K ${ }^{1}$, Parveen B², Rajagopalan V³

\section{HOW TO CITE THIS ARTICLE:}

Selva Prabu S. K, Parveen B, Rajagopalan V. "Porokeratosis of Mibelli with Oral Lesions". Journal of Evolution of Medical and Dental Sciences 2014; Vol. 3, Issue 48, September 29; Page: 11611-11613,

DOI: $10.14260 /$ jemds/2014/3522

ABSTRACT: Porokeratosis of Mibelli is an inherited keratinisation diorder commonly seen in Men. Porokeratosis of Mibelli is common but Porokeratosis of Mibelli with oral mucosal lesions is very very rare. We report a case of Porokeratosis of Mibelli with oral and penile lesions.

KEYWORDS: Porokeratosis of Mibelli, penile porokeratosis of Mibelli, oral lesions of porokeratosis of Mibelli.

INTRODUCTION: Porokeratosis, although the term is a misnomer [1] (since this disorder of keratinistation not necessarily involves the sweat pore always), has got 5 clinical subtypes. They are (i) porokeratosis of Mibelli, (ii) disseminated superficial actinic porokeratosis, (iii) linear porokeratosis, (iv) porokeratosis palmaris plantaris et disseminata, (v) punctate porokeratosis. Oral mucous membrane lesion is very rarely seen in the Mibelli's subtype. ${ }^{[2]}$ Porokeratosis of mucous membrane has been mainly reported from Japan and Italy.[3] To the best of my knowledge, this is the second case report of Porokeratosis of Mibelli with mucous membrane lesions from India.

CASE REPORT: A 36 year old male patient came with the complaints of dark colored raised lesions over the face and hands since 6 yrs of age. It was not associated with itching, pain or burning sensation. He developed similar lesions over his genitalia after 4 yrs. He also developed white raised lesions over his tongue at the age of 14 , which was not associated with any symptoms. No history of similar illness in his family.

On examination, multiple hyper pigmented well defined more or less annular lesions with raised borders are seen over the face, left arm, shaft of penis and in the groin. The lesions are characterised by classical central groove within the raised borders. No scales or ulceration seen. Oral cavity showed few white plaques suggestive of leukoplakia like lesions. Based on the classical skin lesions and the oral cavity lesions, a diagnosis of porokeratosis of mibelli with oral lesions was made.

Specific and supportive investigations like skin biopsy and CBC, LFT, RBS and RFT was done respectively. Skin biopsy showed column of parakeratosis suggestive of Cornoid lamella and focal loss of granular layer beneath the porokeratotic column. Papillary dermis showed perivascular lymphocytic infiltrate. The patient was referred to oral pathology for oral biopsy which showed parakeratotic epithelium. Thus the diagnosis of porokeratosis of mibelli with oral lesions was confirmed. Then the patient was counselled regarding his condition and started treatment with topical calcipotriol and oral retinoids but the patient did not come for follow up later.

DISCUSSION: Porokeratosis is an inherited disorder of keratinisation. An autosomal dominant mode of inheritance with predilection for male sex is well established. Mibelli in 1893, coined the term porokeratosis(3) and later on different clinical types were described one by one. Mucous membrane lesions are very very rare and the mucosa of the mouth, tongue, nose, glans penis and the conjunctiva 
are affected. Previously porokeratosis was thought to be a disorder that involves the eccrine sweat pore. But the mucous membrane involvement, where there is no sweat gland speaks against it. It is now thought that the ring like Cornoid lamella, the hallmark of porokeratosis, may be located in the interadnexal epidermis, acrosyrngium of eccrine sweat duct or within the infundibulum of pilar apparatus.[4]

Porokeratosis of Mibelli has been reported earlier, but only one case of porokeratosis of mibelli with oral lesions were reported earlier by Asok KG.[5] This is the second case of porokeratosis of mibelli with oral lesions being reported. Moreover our patient also has penile porokeratosis of mibelli which is also very rare. Only two cases of penile porokeratosis of mibelli have been reported earlier.[6,7] This case is presented for its rarity.

\section{REFERENCES:}

1. Pinkus H, Mehregan AH. A guide to dermato-histopathology, New York: Appleton Century Crafts, 1976: 491.

2. Mehregan AH, Khalili H, et al. Mibelli's porokeraosis of the face. J Am Acad Dermatol 1980; 3: 394-6.

3. Mikhali GR, Wertheimer FW. Clinical variants of porokeratosis (Mibelli). Arch Dermatol 1968; 98: 124-31.

4. Nabai H, Mehregan AH. Porokeratosis of Mibelli. Dermatologica 1979; 159: 325-31.

5. Asok KG. Porokeratosis of Mibelli with a mucous membrane lesion. Ind J Dermatol 1997; 63: 5354.

6. Ibrahim A, Tangoren MD et al. Penile porokeratosis of Mibelli. J Am Acad Dermatol 1997; 36: 479-81.

7. Levell NJ, Bewley AP, et al. Porokeratosis of Mibelli on the penis, scrotum and natal cleft. Cln Exp Dermatol 1994; 19: 77-8.

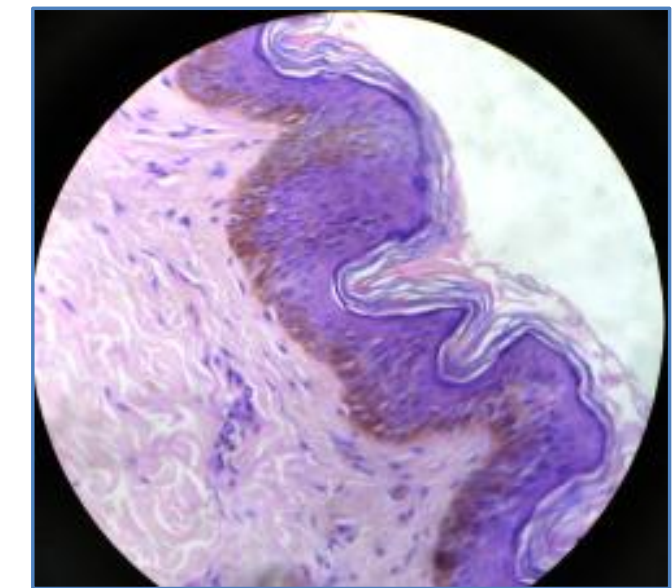

Image 1: Skin biopsy showing porokeratotic cornoid lamellae with focal hypogranulosis beneath it

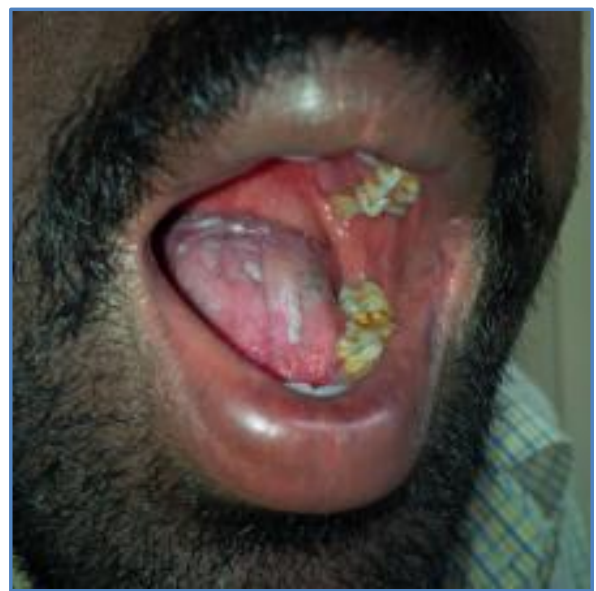

Image 2: Leukoplakia like oral lesions 


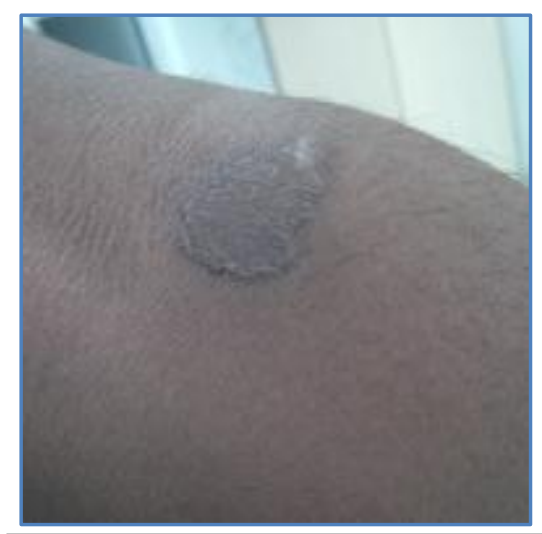

Image 3: Classical skin lesion with a grooved edge

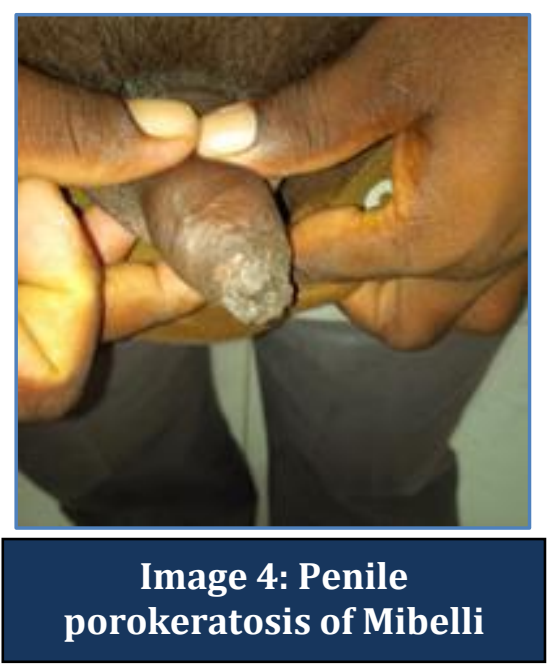

\section{NAME ADDRESS EMAIL ID OF THE CORRESPONDING AUTHOR:}

Dr. S. K. Selva Prabu,

4A, 67, Serenity S,

$1^{\text {st }}$ Main Road,

Nolambur, Mogappair West,

Chennai-600037.

Email: skselvaprabu@gmail.com

Date of Submission: 13/09/2014.

Date of Peer Review: 14/09/2014.

Date of Acceptance: 19/09/2014.

Date of Publishing: 29/09/2014. 